\title{
Thoughts of a Trapper
}

\author{
by
}

\author{
Wilf Wingenroth 1
}

\begin{abstract}
Twenty years of committed backwoods-life as trapper, fisherman and guide in northwestern Ontario's wilderness provided me with experience which eventually led me to criticize man's activities in that environment. Recent logging and roadbuilding are causing severe disruption of trapping. On the other hand, their proximity to my home gives me an ideal "outdoor laboratory" for private study. While I am critical of logging, I also criticize myself as a trapper and trapping in general, and explore the reasons. In particular I challenge concepts of today's resource management such as: "sustained yield", "harvest" and "renewable resource". These have become part of an ideology, leading in many cases to conditions similar to, or worse than, those of the now condemned era of reckless exploitation.
\end{abstract}

Our present management system may be as faulty as were the previous ones, leading to elimination of trapping as we know it.

Key words: wildlife management, trapping, furbearers. resource management.

I have spent almost the entire past two decades living in and off the virgin forest country in northwest Ontario as a trapper, fisherman, and guide. During this time, I have noticed a tremendous escalation in the extent to which the forest is being utilized and exploited.

Trapping is a fairly menial occupation, so my mind has been free to wonder, ponder and worry. Finally, during the last years, logging operations have pushed their way almost into my backyard. This causes hardship, but also gives me the opportunity for close-up study of forestry's effect on trapping and the larger environment. My thoughts on this and my conclusions are not biased or restricted through the teachings of forestry or wildlife management, they are the free thoughts of a practical backwoods dweller and naturalist.

I have discovered for myself some of the underlying reasons behind natural materials extraction and its physical effects, which in turn lead to definable grievances by trappers against the logging industry.

IP.O. Box 432, Sioux Lookout, Ontario POV 2T0
Of these reasons, I plan to speak about only one, the one that I feel is the most important: yet it is virtually never mentioned, namely the philosophy that makes reckless extraction of new materials not only acceptable but even necessary.

Let me throw some unconventional thoughts at you. The ideological leaders of the resource extraction group to which we, the trappers, also belong teach roughly the following, and I paraphrase this, keeping the content correct: That the entire realm of the biosphere may be explored, exploited and utilized, indeed that it has to be utilized or else it will (in simple terms) go bad. We all know the slogan: Use it or you'll lose it. According to this philosophy, all physical features of the biosphere and some nonphysical features as well have been named "natural resources."

Now let me try to refute the notion, that if we don't exploit the natural environment, it will somehow self-destruct. I am referring here to an environment that has not yet been largely altered by man's activities to the degree where a site's normal biological processes have been disturbed. I am definitely not at the moment talking about the populated, built-up or farming sections of this country.

What happened throughout the millennia when human extraction of timber was negligible? Why is it that neither the beaver nor the pine died out during times past? How can we intelligently manage wildlife if we believe in old wives' tales? Isn't it true that this symposium was called for because there are problems all over? Isn't the problem that we have altered and consumed nature faster than it could regenerate? How dare we speak of enhancing, improving, and managing as proudly as we do now? How can we possibly, and I mean in an objective sense, improve on the biological and ecological processes of our natural environment, which we don't even fully understand?

The term "renewable resource" for instance has become an ideological term that is intended to convey a thought that detracts from its real meaning. For example, "Forests are a renewable resource" is a well known slogan. It contains a lie because it implies that natural forests are renewable to their former state. The truth is that wood fiber is a renewable resource, natural forest is not. Also, I understand that there is no intent on the part of governments or the forest industry to recreate natural forests. Logged-over lands are intended to be turned into silvicultural lands. Presumably those areas would then be managed further to produce high-profile game animal species of commercial value.

Another word in question is the term "harvest", a term used almost as often as "managing" and "renewable resource." It's intended to generate a favourable feeling of saneness when 
used in the context of, for example, logging and trapping. Sure one can "harvest" a stand of timber that was planted exclusively for this purpose. One cannot, however, "harvest" a virgin forest or a wild mink without stretching this word past its limit. The term "harvest" becomes the true opposite to the term "murder" in the following example: "Harvesting of juvenile seals" as against "Murdering of baby seals". Of course we know what really goes on here is that seals are being killed for commercial reasons. Both euphemistic terms "harvest" and "murder" are being used to describe the same action depending on how one feels about it.

I am not trying to make a big deal of semantics here. This is far too serious. All the dissected terms and slogans are however, pointing to what is almost an "ideology", and it is this ideology that I am critical of.

There are botanists, specialists in population dynamics, geneticists, ecologists, and zoologists who dispute the possibility of perpetual total exploitation of the biosphere without chancing total destruction of the particular local ecology. Do we aim then, to completely change the ecology of, for instance, all forest lands from a natural self-balancing one to an artificial one that requires total management? Do we feel equipped to accept this responsibility?

Another point in managing is one that deals with quantity over quality. For example, a forested site that does not offer much fibre for commercial use can often support a fastergrowing, larger tree that produces more fiber. From a commercial standpoint, such a tree is often called a superior or plus tree. Such a description may well fly in the face of its breeders at the first unusual storm, or unusual ice and snow load, or climatic variation. Then it becomes clear once again that there was a good reason for the genetic makeup of the site's original trees which were the ecologically superior, though not commercially superior varieties. You have noticed, of course, that in the commercial sense, the words quality and quantity have become somehow muddled. A tree that produces more wood, that is more quantity of fiber, is considered of a higher quality.

While we are talking quality and quantity, let me point to another fallacy that also has commercial roots. For example, it is generally thought that many deer in an area are good and few deer are a sorry state. This leads to a try at generating a strong deer herd while ignoring all other wildlife. A deer herd thus raised has faults similar to a monoculture. Few animals in an environment are just as natural at one time as many are at another. Steady animal populations are not natural, they are artificial.

Let me make another point on management. Nobody here will deny that the aim of commercial forestry is to create monocultural timber plantations. I have observed this endeavour for years and although the objective is far from being met, in time, more effective methods are bound to be developed. The end result will presumably be something similar to the one seen in Europe. The problems that have resulted there are known to most of us. Naturally, integrated management becomes a farce if monocultures prevail. In game management the analogous mistake would be to concentrate management efforts on commercial or high-profile species and ignore the rest. That this is being done cannot be denied.

My vision is - and let me borrow a word - the holistic approach. It is an approach that requires us to recognize the following:

1. that we do not now and probably never will fully understand the natural processes;

2. that these processes are superior to any management schemes we might come up with;

3. that we must not destroy or replace these processes everywhere but only in limited designated areas;

4. that natural materials only be extracted in quantities currently known to be safe and that escalated extraction not be allowed through political pressure, rather that careful research be required before it is allowed;

5. that the integrity of the natural environment be considered above the interests of the users and extractors;

6. that management endeavours not only focus on commercial species but on the total membership of the forest community as well as related communities (I would only speak of integrated management if all species of the community right down to micro-organisms were included in the process); and

7. that wastefulness caused by man's activities be discontinued.

Please don't hesitate to ask me to clarify or qualify any of my statements which seem muddy. You will notice that I have avoided dealing with practical aspects of, in my case, logging versus trapping, other than using some as examples. This is of course intentional. I was dealing with processes, philosophies and attitudes. If the basic attitudes in extraction of natural materials could change, a lot of problems would simply disappear. 